\title{
Review Article \\ Current Applications for the Use of Extracorporeal Carbon Dioxide Removal in Critically Ill Patients
}

\author{
Luigi Camporota and Nicholas Barrett \\ Department of Adult Critical Care, Guy's and St Thomas' NHS Foundation Trust, King's Health Partners, \\ St Thomas' Hospital, 1st Floor East Wing, Westminster Bridge Road, London SE1 7EH, UK
}

Correspondence should be addressed to Luigi Camporota; luigi.camporota@gstt.nhs.uk

Received 1 December 2015; Accepted 20 January 2016

Academic Editor: Christophe Guervilly

Copyright (C) 2016 L. Camporota and N. Barrett. This is an open access article distributed under the Creative Commons Attribution License, which permits unrestricted use, distribution, and reproduction in any medium, provided the original work is properly cited.

Mechanical ventilation in patients with respiratory failure has been associated with secondary lung injury, termed ventilatorinduced lung injury. Extracorporeal venovenous carbon dioxide removal $\left(\mathrm{ECCO}_{2} \mathrm{R}\right)$ appears to be a feasible means to facilitate more protective mechanical ventilation or potentially avoid mechanical ventilation in select patient groups. With this expanding role of $\mathrm{ECCO}_{2} \mathrm{R}$, we aim to describe the technology and the main indications of $\mathrm{ECCO}_{2} \mathrm{R}$.

\section{Introduction}

Respiratory failure-a condition in which the respiratory system is unable to maintain adequate gas exchange to satisfy metabolic demands-is the most common cause of admission to critical care, and because of the increase of life expectancy in industrialized countries, respiratory diseases will represent the third most common cause of death by 2025. An important syndrome leading to respiratory failure in critically ill patients is the acute respiratory distress syndrome (ARDS), which leads to poor lung function with hypoxaemia, hypercapnia, and low respiratory system compliance.

In these conditions, mechanical ventilation is often able to provide adequate oxygenation and $\mathrm{CO}_{2}$ removal. However, the improvement of gas exchange commonly occurs at the expense of a secondary injury to the lung (ventilator-induced lung injury or VILI) due to inhomogeneous lung overdistension. VILI can lead to the release of inflammatory mediators that reach other organs causing multiple organ failure [1]. This has led to the concept of protective mechanical ventilation with limited tidal volume and plateau pressure. Application of protective ventilator strategies is associated with decreased serum cytokine levels [2], decreased extra-pulmonary organ dysfunction [3], and decreased mortality [4].

In the last 15 years it has become evident that targets of mechanical ventilation traditionally considered "protective" are often unable to offer lung protection particularly in the more severe cases of lung injury. This has led to the concept of an "ultraprotective" ventilation strategy which employs even lower tidal volumes, a lower respiratory rate, lower driving pressures, and lower plateau pressures while maintaining an adequate mean airway pressure to avoid a reduction in functional residual capacity.

Ultraprotective ventilation strategies are likely to lead to hypercapnia and its deleterious consequences including systemic and cerebral vasodilatation, cardiovascular depression, arrhythmia, and pulmonary vasoconstriction with an increase in pulmonary arterial pressure. Acute pulmonary hypertension increases RV afterload and causes acute cor pulmonale which is associated with high mortality rates [5]. The need to correct hypercapnia without exposing the lung to mechanical trauma has resulted in a renewed interest in extracorporeal technologies that facilitate extracorporeal $\mathrm{CO}_{2}$ removal $\left(\mathrm{ECCO}_{2} \mathrm{R}\right)$.

\section{Definition}

$\mathrm{ECCO}_{2} \mathrm{R}$ is a technique of partial respiratory support that achieves removal of $\mathrm{CO}_{2}$ from the blood through a low blood flow $(0.4-1 \mathrm{~L} / \mathrm{min})$ extracorporeal circuit, without significant effect on blood oxygenation. This is in comparison to extracorporeal membrane oxygenation which uses blood flows of 3-7 L/min to provide total respiratory support with significant oxygenation and $\mathrm{CO}_{2}$ removal. In many expert centres 
the devices used to provide ECMO and $\mathrm{ECCO}_{2} \mathrm{R}$ support are the same and given that the key difference is blood flow rates, there is considerable overlap between the two techniques. Indeed, some authors refer to low-flow ECMO rather than $\mathrm{ECCO}_{2} \mathrm{R}$ in order to acknowledge this continuum. Through $\mathrm{ECCO}_{2} \mathrm{R}$ a proportion of the total $\mathrm{CO}_{2}$ production is cleared to allow reduction of mechanical ventilation and allow "lung rest" [6]. Although the original purpose for $\mathrm{ECCO}_{2} \mathrm{R}$ was to provide additional $\mathrm{CO}_{2}$ clearance in patients with severe ARDS to allow reduction in tidal volumes and inspiratory pressures, its applications are extending to include patients with Chronic Obstructive Pulmonary Disease (COPD) and as a bridge to transplant or in order to facilitate thoracic surgery.

\section{3. $\mathrm{ECCO}_{2} \mathrm{R}$ Gas Exchange Physiology}

The oxygenation of blood and the removal of carbon dioxide $\left(\mathrm{CO}_{2}\right)$ are physiologically different. Oxygen is mainly transported bound to haemoglobin, rather than being dissolved, and the mixed venous blood generally has high saturation (65-70\%), which limits the amount of oxygen per litre that can be added to the blood perfusing the natural or the extracorporeal lung. This makes blood oxygenation dependent on blood flow (on average $4-7 \mathrm{~L} / \mathrm{min}$ ). In contrast, $\mathrm{CO}_{2}$ exchange depends on ventilation or, in the case of a membrane, gas flow (termed sweep gas flow). The sweep gas contains little or no $\mathrm{CO}_{2}$ and is passed through the membrane on the other side of a semipermeable membrane to the blood, thereby creating a diffusion gradient, which allows $\mathrm{CO}_{2}$ removal. By using a sweep gas of up to $100 \%$ oxygen at high flows, the gradient in partial pressure of oxygen and $\mathrm{CO}_{2}$ across the membranes separating the blood from gas can be significantly higher than the gradient across the capillary and alveolar wall in the native lungs.

Considering that $1 \mathrm{~L}$ of blood is transported around $500 \mathrm{~mL}$ of $\mathrm{CO}_{2}$ (double the $\mathrm{CO}_{2}$ production per minute, about $200-250 \mathrm{~mL} / \mathrm{min}$ ), in a perfectly efficient system a flow of $0.5 \mathrm{~L} / \mathrm{min}$ would be sufficient to remove all of the $\mathrm{CO}_{2}$ produced [3, 7-9]. However, in practice $\mathrm{CO}_{2}$ removal at any given blood flow depends upon the gas flow and blood $\mathrm{CO}_{2}$ content and haemoglobin [10] as well as the efficiency of the gas exchange membrane. These limit the amount of $\mathrm{CO}_{2}$ removed from the blood and $\mathrm{ECCO}_{2} \mathrm{R}$ is usually able to remove up to $25 \%$ of carbon dioxide production [6]. Blood flow is of course also important and $\mathrm{CO}_{2}$ removal also varies with changes in blood flow through the device [4]. Apart from the fact that $\mathrm{CO}_{2}$ removal is proportional to the $\mathrm{PaCO}_{2}$, sweep gas flow, and blood flow, it also exhibits biphasic removal kinetics, exemplified by the initial rapid decline in $\mathrm{PaCO}_{2}$ secondary to removal of the dissolved $\mathrm{CO}_{2}$ and then followed by a more steady removal of $\mathrm{CO}_{2}$, liberated from bicarbonate [11].

\section{Description of $\mathrm{ECCO}_{2} \mathrm{R}$ Systems}

$\mathrm{ECCO}_{2} \mathrm{R}$ systems vary in characteristics, technology, and ability of gas exchange. They range from renal dialysis systems (low blood flow and low priming volume) to partial extracorporeal support $\left(\mathrm{ECCO}_{2} \mathrm{R}\right)$ up to systems capable of full ECMO support with the capability of removing all $\mathrm{CO}_{2}$ production and providing flows high enough to increase oxygen delivery and therefore provide blood oxygenation. An $\mathrm{ECCO}_{2} \mathrm{R}$ circuit consists of a percutaneously placed drainage cannula placed in a large central vein (or artery), a membrane lung, and a return cannula into the venous system. In the case of arteriovenous (AV) systems, the patient's blood pressure provides the driving pressure across the membrane. Venovenous systems require a pump to be placed within the circuit.

\section{Access Cannulae}

Access to the circulation is gained either through separate arterial and venous cannulae (AV systems) or by using double-lumen cannulae (VV systems).

The AV system requires two single-lumen wirereinforced cannulae, one in the femoral artery to access blood and one in the femoral vein to return the blood to the venous side. The venous cannula is usually larger than the arterial cannula in order to reduce resistance to blood flow. The key disadvantage of the AV approach is the need for arterial cannulation with the potential side effects of arterial injury and limb ischaemia. In reported series distal ischaemia occurs in $11-24 \%$ of cases [12, 13]. The risk of ischaemia relates directly to the diameter of the arterial cannula. It is recommended that ultrasound of the artery takes place prior to cannulation to ensure that the arterial lumen is at least 1.5 times the size of the arterial cannula. Arterial injury is reported to occur in 7.5\%-10\% of cannulation cases $[12,14]$ for $\mathrm{ECCO}_{2} \mathrm{R}$ and is thought to relate to operator experience, patient factors including peripheral vascular disease, and size of arterial cannula. In the AV approach, flow is of course directly related to arterial cannula diameter and the risk of inadequate blood flow has to be balanced against the risk of arterial injury and limb ischaemia.

Cannulae for VV ECCO 2 R are conceptually identical to dialysis catheters. They are wire-reinforced, double-lumen coaxial cannulae between 13 and $19 \mathrm{Fr}$. Some cannulae have heparin coatings to reduce the risk of thrombosis. They can be placed in any large central vein although the jugular and femoral approaches are most commonly used [15]. The cannulae used for $\mathrm{ECCO}_{2} \mathrm{R}$ have the same complications as any central venous cannula, including risk of vessel perforation leading to bleeding or damage to surrounding structures, for example, pneumothorax or arterial injury [16].

Regardless of the approach chosen, cannulae are inserted using a percutaneous Seldinger technique. Ultrasound has been shown to reduce the risk of complications relating to central venous and ECMO cannula insertion and it would seem prudent to use ultrasound guidance for $\mathrm{ECCO}_{2} \mathrm{R}$. Similarly it would seem prudent to observe strict aseptic technique during cannula insertion as this has been demonstrated to reduce complications relating to central venous cannula insertion. Not all cannulae are heparin bonded and 
either flushing with a heparinized saline solution or systemic anticoagulation with heparin will be required at the time of cannulation to prevent thrombosis of the cannula.

\section{The Membrane Lung}

The concept of placing a barrier between blood and air began with the observation that gas exchange occurred across cellophane tubing in haemodialysis machines $[7,17]$. Indeed the membrane lung is conceptually very similar to modern haemodialysis filters using capillary tubules to carry blood through the oxygenator and separate tubules to carry the sweep gas. Recently, nonmicroporous poly-4-methyl1-pentene (PMP) has been used; it provides superior gas exchange, better biocompatibility, and lower resistance and is less susceptible to plasma leak [7]. Modern membrane lungs achieve adequate gas exchange with surface areas of 1 to $3 \mathrm{~m}^{2}$. The gas exchange membrane is connected to air or oxygen which acts as a "sweep gas" to remove $\mathrm{CO}_{2}$ that has diffused out of the patient's blood. The flow rate of oxygen is increased in a stepwise fashion up to a maximum of $12 \mathrm{~L} / \mathrm{min}$.

\section{The Pump}

Blood flows through the $\mathrm{ECCO}_{2} \mathrm{R}$ circuits can occur in two ways.

(1) The first one is using the patient's own arterial blood pressure (pumpless systems), where arterial blood is accessed through an arterial cannula and returned to the venous system via a venous cannula. These systems (arteriovenous, or AV $\mathrm{ECCO}_{2} \mathrm{R}$ ) have the advantage of not requiring a mechanical pump. They therefore tend to be simpler and cheaper but have the disadvantage of requiring arterial cannulation with the potential side effects of arterial injury and limb ischaemia. The AV $\mathrm{ECCO}_{2} \mathrm{R}$ circuit introduces a low resistance iatrogenic shunt between the arterial and venous systems thereby reducing systemic vascular resistance and a compensatory increase in cardiac output to maintain systemic arterial perfusion pressure. In addition, the proportion of the cardiac output that flows through the $\mathrm{ECCO}_{2} \mathrm{R}$ system is not involved in peripheral perfusion; hence the patient's effective cardiac output is reduced. Furthermore, for optimal functioning, a mean arterial pressure of $70 \mathrm{mmHg}$ and a cardiac index $>3 \mathrm{~L} / \mathrm{min} / \mathrm{m}^{2}$ are required [18]. For that reason cardiac failure, severe haemodynamic instability, and severe peripheral vascular disease are a contraindication to $\mathrm{AV} \mathrm{ECCO}_{2} \mathrm{R}$.

(2) Alternatively, blood flow can be achieved through a mechanical pump. The pump and the membrane can be separate components or can form a single console. Pumps can be roller or peristaltic (older systems) or rotary pumps, which can be "diagonal" or "centrifugal" where a rotating impeller creates a suction vortex that draws blood into the centre of the pump and propels it outwards from the outlet.

\section{Experimental Evidence for Efficacy of $\mathrm{CO}_{2}$ Removal}

Regardless of whether the AV or VV approach is used, $\mathrm{ECCO}_{2} \mathrm{R}$ devices can remove enough $\mathrm{CO}_{2}$ to allow a $50 \%$ reduction in minute alveolar ventilation [19], with significant reduction in $\mathrm{PaCO}_{2}$ and consequent reduction in pulmonary artery pressure and improvement in RV-arterial coupling even with flows as low as $0.6-0.7 \mathrm{~L} / \mathrm{min}$ and average sweep gas flow of $8 \mathrm{~L} / \mathrm{min}$ [20]. Livigni et al., in an adult sheep model, were able to obtain a constant removal of arterial $\mathrm{CO}_{2}$, with an average $20 \%$ reduction in $\mathrm{CO}_{2}$, with extracorporeal blood flow of $300 \mathrm{~mL} / \mathrm{min}$ (around $5 \%$ of cardiac output) [21]. Other animal studies have demonstrated that the devices can maintain consistent $\mathrm{CO}_{2}$ removal for over 7 days using a low-flow VV approach [22]. Novel methods to maximize $\mathrm{CO}_{2}$ removal, such as regional blood acidification which increases the bioavailability of $\mathrm{CO}_{2}$ by unbinding it from the bicarbonate ion in circulating blood, are also under investigation $[23,24]$.

\section{Clinical Evidence for Efficacy of $\mathrm{CO}_{2}$ Removal}

In the mid-late 1970s Kolobow, Gattinoni, and Pesenti pioneered the use of venovenous $\mathrm{ECCO}_{2} \mathrm{R}$ for partial-to-total $\mathrm{CO}_{2}$ removal to allow low-frequency ventilation and lung rest [25-27]. In addition, these authors showed that the removal of one-third of the basal $\mathrm{CO}_{2}$ production through the extracorporeal circuit at flows of $400-600 \mathrm{~mL} / \mathrm{min}$ allowed reduction of tidal volumes and the switch to noninvasive ventilation $[28,29]$. Early clinical trials, however, did not show positive outcomes and the complication rate-particularly bleeding-was elevated [30-33]. In 1980, Gattinoni et al. showed that ECMO with a blood flow as low as $1.3 \mathrm{~L} / \mathrm{min}$ drastically reduced ventilation needs (respiratory frequency of 2-3 breaths/min) thus limiting ventilator-induced lung injury [27]. A subsequent observational study of 23 patients with severe ARDS [34] demonstrated the ability of $\mathrm{ECCO}_{2} \mathrm{R}$ to allow reduction in respiratory rate and inflation pressures while maintaining $\mathrm{CO}_{2}$ clearance and supporting oxygenation. Bleeding was significant in this series and was the reported cause of death in 4/23 patients.

More recent series in humans have demonstrated consistent evidence that $\mathrm{PaCO}_{2}$ can be reduced and arterial $\mathrm{pH}$ due to respiratory acidosis improved using $\mathrm{ECCO}_{2} \mathrm{R}$ [35]. AV $\mathrm{ECCO}_{2} \mathrm{R}$ has also been shown to reduce minute ventilation in an uncontrolled cohort of 159 patients over 10 years showed [18]. Similarly VV ECCO${ }_{2} \mathrm{R}$ can effectively reduce $\mathrm{PaCO}_{2}$ in patients with ARDS and can facilitate a reduction in both tidal volume and airway pressures $[7,9]$.

\section{Current Evidence}

The current evidence supporting applications for $\mathrm{ECCO}_{2} \mathrm{R}$ is extremely limited. Most published data is at the level of observational, retrospective case series. Consequently there is inherent bias including selection bias and complications 
and outcomes need to be interpreted with an understanding that the case series mainly originate from expert centres. At present $\mathrm{ECCO}_{2} \mathrm{R}$ should be considered a research tool, rather than an accepted clinical procedure. There is a clear need for further robust research, particularly prospective, randomized, controlled studies.

\section{ARDS}

Besides the general improvement in the standard of care provided in the intensive care units (ICUs), the only specific management that has consistently been shown to reduce mortality in ARDS is the provision of mechanical ventilation with static inspiratory pressures (plateau pressure) of less than $30 \mathrm{~cm} \mathrm{H}_{2} \mathrm{O}$ and low tidal volumes normalised to predicted body weight (PBW) according to a concept known as "lungprotective ventilation" (LPV). This strategy has been shown to reduce ventilator-induced lung injury (VILI) and is linked to improvements in short and long term outcomes for the majority of patients [36].

However, despite this global improvement in survival, there is a cohort of patients with severe hypoxaemia $\left(\mathrm{PaO}_{2} / \mathrm{FiO}_{2}<13.3 \mathrm{kPa}\right)$ and hypercapnia (leading to a $\mathrm{pH}<$ 7.20) who offer a significant therapeutic challenge. This group of patients, even when managed with optimal recruitment and LPV, have a significantly higher mortality than patients with a higher $\mathrm{PaO}_{2} / \mathrm{FiO}_{2}$ ratio or lower $\mathrm{PaCO}_{2}$ for any given minute ventilation [37-39]. It is likely that the identification of this subgroup of patients with "severe" ARDS will be made more explicit in the new "Berlin definition of ARDS" [40], allowing for targeted therapeutic interventions and further clinical studies.

One of the potential rationales for the poorer outcomes in patients with more severe ARDS is that, due to the extent of lung consolidation and alveolar injury, the available lung volume is small. Hence the use of conventional low tidal volume ventilation ( $6 \mathrm{~mL} / \mathrm{Kg}$ ideal body weight) when administered into a smaller available lung volume will yield excessive lung strain. Terragni et al. [41] demonstrated that up to one-third of patients receiving LPV had evidence of tidal hyperinflation and hence lung injury. One of the reasons for maintaining a conventional lung-protective ventilation approach is to limit the hypercapnia and consequent respiratory acidosis that will develop with very low minute ventilation. Although permissive hypercapnia has been advocated, hypercapnia may cause significant physiological instability including pulmonary hypertension and right ventricular failure leading to a global low cardiac output state. In these patients, the addition of $\mathrm{ECCO}_{2} \mathrm{R}$ may allow control of hypercapnic respiratory acidosis and facilitate ultraprotective ventilation thereby limiting end-inspiratory lung stretch. It is possible that this approach may improve patient outcome.

In 1994, Brunet et al. used extracorporeal $\mathrm{CO}_{2}$ removal combined with low-frequency positive pressure ventilation $\left(\mathrm{ECCO}_{2} \mathrm{R}-\mathrm{LFPPV}\right)$ in severe ARDS. They showed that $\mathrm{ECCO}_{2} \mathrm{R}$ improved gas exchange and prevented lung overinflation [42]. However, the same year Morris et al., in a randomized trial, showed that in patients with severe ARDS full $\mathrm{ECCO}_{2} \mathrm{R}$ (meaning $100 \% \mathrm{CO}_{2}$ removal) compared to conventional mechanical ventilation had a lower mortality of $33 \%$ versus $42 \%$ for the control group which failed to achieve statistical significance. The authors did not recommend extracorporeal support as a therapy for ARDS outside controlled clinical trials [43]. Subsequent studies have confirmed efficacy of $\mathrm{ECCO}_{2} \mathrm{R}$ in removing $\mathrm{CO}_{2}$ allowing reduction in tidal volumes to and below $4 \mathrm{~mL} / \mathrm{kg}$ [44] but with high mortality and complications [12, 45]. Similarly, Zimmermann et al. showed that when $\mathrm{ECCO}_{2} \mathrm{R}$ was used as rescue in more severe ARDS $\left(\mathrm{PaO}_{2} / \mathrm{FiO}_{2}\right.$ ratio $<100 \mathrm{mmHg}$ and/or $\mathrm{pH}$ $<7.25$ after a 24-hour period of optimized ventilation) it achieved marked removal in arterial carbon dioxide allowing a rapid reduction in tidal volume $(<$ or $=6 \mathrm{~mL} / \mathrm{kg})$ and inspiratory plateau pressure. Adverse events occurred in six patients (11.9\%) [13]. The high mortality and disappointing effect of $\mathrm{ECCO}_{2} \mathrm{R}$ in the early use of $\mathrm{ECCO}_{2} \mathrm{R}$ were likely to be due to the complex extracorporeal systems with high flow resistances and large surface areas $\left(3.5 \mathrm{~m}^{2}\right)$, the use of occlusive roller pumps (with high haemolysis rate), and a less biocompatible membrane requiring high anticoagulation levels. In addition mechanical ventilation was in the preARDSNet era and employed high tidal volumes and peak pressures.

Terragni et al. used VV ECCO 2 R in 32 ARDS patients to facilitate "ultraprotective" ventilation of $4 \mathrm{~mL} / \mathrm{kg}$ [46]. VV $\mathrm{ECCO}_{2} \mathrm{R}$ treated the hypercapnic acidosis and allowed the plateau pressure to be reduced to $25 \mathrm{~cm} \mathrm{H}_{2} \mathrm{O}$ to deliver $4 \mathrm{~mL} / \mathrm{kg}$ ideal body weight tidal volume. Importantly the reduction in tidal volume did lead to tidal derecruitment and higher oxygen fraction; consequently there was a need for higher levels of positive end-expiratory pressure [PEEP] to maintain lung recruitment and functional residual capacity. The reduction in airway pressures seems to have reduced pulmonary inflammation as demonstrated by a reduction in bronchoalveolar inflammatory cytokines. In the prospective randomized "Xtravent-study," Bein et al. [47] demonstrated that use of very low tidal volumes $(3 \mathrm{~mL} / \mathrm{kg}$ PBW) combined with $\mathrm{ECCO}_{2} \mathrm{R}$ with an arteriovenous configuration was safe and beneficial in patients with severe ARDS in terms of 28 and 60 ventilator-free days, but not mortality. A post hoc analysis showed increase in ventilation-free days at 60 days in patients with severe hypoxaemia $\left(\mathrm{PaO}_{2} / \mathrm{FiO}_{2}<20 \mathrm{kPa}\right)$ [47]. A recent systematic review of 14 studies (495 patients, two RCTs and 12 observational studies) with equal split between $\mathrm{AV}$ and $\mathrm{VV} \mathrm{ECCO}_{2} \mathrm{R}$ showed that $\mathrm{ECCO}_{2} \mathrm{R}$ was feasible, facilitating the use of lower tidal volume ventilation [16], and post hoc analysis of data shows an increase in ventilator-free days in more severe ARDS although there has been no demonstrable mortality benefit to date.

Therefore, although the addition of $\mathrm{ECCO}_{2} \mathrm{R}$ to ultraprotective ventilation is appealing for patients with moderateto-severe ARDS, at this time the effect of this approach on survival remains inconclusive $[15,42,45]$. Clearly the potential risk-benefit relationships still need to be defined, with the advantages of tidal volume/airway plateau pressure minimization being balanced against these risks associated 
with $\mathrm{ECCO}_{2} \mathrm{R}$ and derecruitment [16]. Finally we do not currently know which patient cohort is the key population to target. Patients with more severe respiratory failure $\left(\mathrm{PaO}_{2} / \mathrm{FiO}_{2}<20 \mathrm{kPa}\right)$ may be an appropriate population of patients, as, according to UK Intensive Care National Audit and Research Centre (ICNARC), this cohort has a $40 \%$ ICU mortality and around 50\% hospital mortality. Clearly further research is required before this approach can be advised outside of clinical trials.

\section{COPD}

Patients who present with an acute hypercapnic respiratory failure due to a severe exacerbation of COPD often require hospitalization and noninvasive respiratory support (NIV) [5]. However, NIV fails to improve $25-50 \%$ of COPD patients who then require invasive positive pressure ventilation [48, 49]. These patients have prolonged weaning, and in-hospital mortality is as high as $25-39 \%[3,6-9,52]$. Of concern, the mortality for patients who require invasive MV after failing NIV has been shown to be higher than those who are treated at the outset with invasive MV [6]. It is not clear why this is the case; however ventilator associated pneumonia is common in COPD patients requiring invasive mechanical ventilation and this has been shown to be an independent predictor of increased ICU mortality with mortality as high as $60-64 \%$ and VAP $[50,51]$.

In severe COPD exacerbations, high airway resistance, ventilation/perfusion mismatch, dynamic hyperinflation, and increased work of breathing with increased $\mathrm{CO}_{2}$ production lead to hypercapnia. Given the outcomes of patients requiring mechanical ventilation its avoidance in this population is potentially of clinical benefit. For this reason, $\mathrm{ECCO}_{2} \mathrm{R}$ is being considered as an adjunctive therapy to NIV to facilitate the withdrawal of NIV, avoid intubation, or facilitate early extubation. The feasibility of using venovenous $\mathrm{ECCO}_{2} \mathrm{R}$ for acute hypercapnic respiratory failure due to $\mathrm{COPD}$ exacerbations has been demonstrated in several recent cases and cohort studies [52-55].

A recent retrospectively propensity matched cohort study found that $\mathrm{AV} \mathrm{ECCO}_{2} \mathrm{R}$ was able to consistently reduce $\mathrm{PaCO}_{2}$, improve respiratory acidosis, and reduce respiratory rate in 21 patients suffering from acute hypercapnic respiratory failure (mainly COPD) who were failing NIV [56]. In this retrospectively matched cohort study $90 \%$ of the patients treated with $\mathrm{AV} \mathrm{ECCO}_{2} \mathrm{R}$ did not require intubation and invasive mechanical ventilatory support, and there was a trend in this group towards a reduced length of hospital stay, but not mortality.

Another recent study by Burki and colleagues reported on VV ECCO ${ }_{2} \mathrm{R}$ using a dual-lumen venous catheter in COPD patients with hypercapnic respiratory failure. Three groups of patients were studied: patients with a high likelihood of requiring intubation; patients who had failed two weaning attempts from continuous NIV support and did not wish to be intubated; or patients already on invasive ventilation to assist weaning in them [54]. $\mathrm{PaCO}_{2}$ and $\mathrm{pH}$ improved within 6 hours and there were minimal major complications of the technique. All patients in whom the goal was intubation avoidance or weaning from NIV achieved remained ventilator-free and separated from NIV. The approach was less successful in patients where early extubation was the goal in this study. However a feasibility study by Abrams et al. [52] enrolled five patients with acute respiratory acidosis in the setting of COPD exacerbations who had failed NIV and required IMV and were initiated on $\mathrm{ECCO}_{2} \mathrm{R}$ to facilitate endotracheal extubation and mobilization. All five patients were successfully extubated within $24 \mathrm{~h}$ (median duration, $4 \mathrm{~h}$ ) and ambulating within $48 \mathrm{~h}$ of $\mathrm{ECCO}_{2} \mathrm{R}$ support. Furthermore dyspnea improved as the respiratory acidosis resolved. This approach of using $\mathrm{ECCO}_{2} \mathrm{R}$ after NIV failure was also used successfully in a small study by Roncon-Albuquerque et al. [53]. Finally there has been a recent retrospective cohort study using historical controls reported from Italy where 25 patients at high risk of NIV failure who received $\mathrm{ECCO}_{2} \mathrm{R}$ via a $14 \mathrm{Fr}$ dual-lumen cannula in the femoral vein had lower intubation rates (HR 0.27) and a lower mortality [57]. Thirty-six percent of patients experienced device malfunctions and $12 \%$ of patients had bleeding complications, including one vessel perforation.

In summary the arguments for $\mathrm{ECCO}_{2} \mathrm{R}$ in exacerbations of COPD are compelling, although the evidence remains relatively weak. In patients who are failing NIV and who do not want intubation but also do not want palliative care $\mathrm{ECCO}_{2} \mathrm{R}$ seems a reasonable approach [58].

\section{Thoracic Surgery}

A few case reports show that $\mathrm{ECCO}_{2} \mathrm{R}$ has been successfully applied to patients who underwent elective or emergency thoracic surgery, to allow surgery in patients who would not have tolerated one-lung ventilation [59].

\section{Bridge to Transplant}

A further group of patients-those awaiting lung transplantation who develop life-threatening hypercapnia-may benefit from $\mathrm{ECCO}_{2} \mathrm{R}$ as bridge to transplantation (LTX). The concept behind using $\mathrm{ECCO}_{2} \mathrm{R}$ as a bridge to transplantation is that it is known that when patients waiting for lung transplantation have an acute deterioration requiring mechanical ventilation, their mortality is substantially increased when compared with those patients who do not require mechanical ventilation. Consequently, clinicians have used $\mathrm{ECCO}_{2} \mathrm{R}$ in selected hypercapnic patients in an attempt to avoid mechanical ventilation, in the hope that this will improve the likelihood of survival. The possible advantages of $\mathrm{ECCO}_{2} \mathrm{R}$ are the avoidance of intubation and mechanical ventilation and their potential adverse sequelae, continuation of physiotherapy and allowing the patient to remain autonomous. $\mathrm{ECCO}_{2} \mathrm{R}$ does have significant potential problems, including the need for anticoagulation and significant uncertainty as to the outcomes of patients awaiting transplantation supported with $\mathrm{ECCO}_{2} \mathrm{R}$. To date there have been no randomized controlled trials performed utilizing this approach. 
In a study of 20 patients, the most common underlying diagnoses were bronchiolitis obliterans syndrome, cystic fibrosis, and idiopathic pulmonary fibrosis. Hypercapnia and acidosis were effectively corrected in all patients within the first $12 \mathrm{~h}$ of $\mathrm{ECCO}_{2} \mathrm{R}$ therapy: nineteen patients (95\%) were successfully transplanted. Hospital and 1-year survival were 75 and $72 \%$, respectively [60]. AV $\mathrm{ECCO}_{2} \mathrm{R}$ devices have also been surgically implanted from the pulmonary artery to left atrium as a bridge to lung transplantation in patients with significant pulmonary hypertension [31]. Patients have similarly been successfully bridged to lung transplant using VV ECCO 2 R [44, 59-61]. The use of $\mathrm{ECCO}_{2} \mathrm{R}$ as a bridge to transplantation does appear promising in the case series reported to date; however significant further studies are required in order to confirm that this approach is appropriate and improves outcomes. Use of $\mathrm{ECCO}_{2} \mathrm{R}$ in patients awaiting transplantation should only be considered by expert centres with a balance of risk and benefit to the individual patient considered.

\section{Conclusions}

Technological advances in $\mathrm{ECCO}_{2} \mathrm{R}$, together with the recognition that ventilation-induced lung injury can occur despite lung-protective ventilation, have created the opportunity for an extended role of partial extracorporeal $\mathrm{CO}_{2}$ removal. Future applications will involve smaller and more biocompatible $\mathrm{ECCO}_{2} \mathrm{R}$ systems, for patients with moderate-severe ARDS but also as a sole supportive modality in patients with hypercapnic respiratory failure. The potential complications of $\mathrm{ECCO}_{2} \mathrm{R}$ need to be evaluated when considering patients for extracorporeal support.

\section{Conflict of Interests}

The authors have no personal financial interests to disclose.

\section{References}

[1] A. S. Slutsky and V. M. Ranieri, "Ventilator-induced lung injury," The New England Journal of Medicine, vol. 369, no. 22, pp. 21262136, 2013.

[2] P. Terragni, V. M. Ranieri, and L. Brazzi, "Novel approaches to minimize ventilator-induced lung injury," Current Opinion in Critical Care, vol. 21, no. 1, pp. 20-25, 2015.

[3] L. Gattinoni, A. Pesenti, T. Kolobow, and G. Damia, "A new look at therapy of the adult respiratory distress syndrome: motionless lungs," International Anesthesiology Clinics, vol. 21, no. 2, pp. 97117, 1983.

[4] C. Karagiannidis, K. A. Kampe, F. S. Sipmann et al., "Venovenous extracorporeal $\mathrm{CO}_{2}$ removal for the treatment of severe respiratory acidosis: pathophysiological and technical considerations," Critical Care, vol. 18, no. 3, article R124, 2014.

[5] P. Morimont, A. Batchinsky, and B. Lambermont, "Update on the role of extracorporeal $\mathrm{CO}_{2}$ removal as an adjunct to mechanical ventilation in ARDS," Critical Care, vol. 19, no. 1, article 117, 2015.
[6] P. Terragni, G. Maiolo, and V. M. Ranieri, "Role and potentials of low-flow $\mathrm{CO}_{2}$ removal system in mechanical ventilation," Current Opinion in Critical Care, vol. 18, no. 1, pp. 93-98, 2012.

[7] M. E. Cove, G. MacLaren, W. J. Federspiel, and J. A. Kellum, "Bench to bedside review: extracorporeal carbon dioxide removal, past present and future," Critical Care, vol. 16, no. 5, article 232, 2012.

[8] G. MacLaren, A. Combes, and R. H. Bartlett, "Contemporary extracorporeal membrane oxygenation for adult respiratory failure: life support in the new era," Intensive Care Medicine, vol. 38, no. 2, pp. 210-220, 2012.

[9] A. Pesenti, N. Patroniti, and R. Fumagalli, "Carbon dioxide dialysis will save the lung," Critical Care Medicine, vol. 38, no. 10, supplement, pp. S549-S554, 2010.

[10] M. Park, E. L. V. Costa, A. T. Maciel et al., "Determinants of Oxygen and Carbon Dioxide Transfer during Extracorporeal Membrane Oxygenation in an Experimental Model of Multiple Organ Dysfunction Syndrome," PLoS ONE, vol. 8, no. 1, Article ID e54954, 2013.

[11] T. Müller, M. Lubnow, A. Philipp et al., "Extracorporeal pumpless interventional lung assist in clinical practice: determinants of efficacy," European Respiratory Journal, vol. 33, no. 3, pp. 551$558,2009$.

[12] T. Bein, F. Weber, A. Philipp et al., "A new pumpless extracorporeal interventional lung assist in critical hypoxemia/ hypercapnia," Critical Care Medicine, vol. 34, no. 5, pp. 13721377, 2006.

[13] M. Zimmermann, T. Bein, M. Arlt et al., "Pumpless extracorporeal interventional lung assist in patients with acute respiratory distress syndrome: a prospective pilot study," Critical Care, vol. 13, no. 1, article R10, 2009.

[14] T. Bein, T. Muller, B. M. Graf et al., "Factors of tidal volume variation during augmented spontaneous ventilation in patients on extracorporeal carbon dioxide removal. A multivariate analysis," Minerva Anestesiologica, vol. 81, no. 1, pp. 28-32, 2015.

[15] C. E. Ventetuolo and C. S. Muratore, "Extracorporeal life support in critically ill adults," American Journal of Respiratory and Critical Care Medicine, vol. 190, no. 5, pp. 497-508, 2014.

[16] M. Fitzgerald, J. Millar, B. Blackwood et al., "Extracorporeal carbon dioxide removal for patients with acute respiratory failure secondary to the acute respiratory distress syndrome: a systematic review," Critical Care, vol. 18, no. 3, article 222, 2014.

[17] W. J. Kolff, H. T. Berk, M. ter Welle, L. A. van der Ley, E. C. van Dijk, and J. van Noordwijk, "The artificial kidney: a dialyser with a great area. 1944," Journal of the American Society of Nephrology, vol. 8, no. 12, pp. 1959-1965, 1997.

[18] B. Flörchinger, A. Philipp, A. Klose et al., "Pumpless extracorporeal lung assist: a 10-year institutional experience," Annals of Thoracic Surgery, vol. 86, no. 2, pp. 410-417, 2008.

[19] A. I. Batchinsky, B. S. Jordan, D. Regn et al., "Respiratory dialysis: reduction in dependence on mechanical ventilation by venovenous extracorporeal $\mathrm{CO}_{2}$ removal," Critical Care Medicine, vol. 39, no. 6, pp. 1382-1387, 2011.

[20] P. Morimont, J. Guiot, T. Desaive et al., "Veno-venous extracorporeal $\mathrm{CO}_{2}$ removal improves pulmonary hemodynamics in a porcine ARDS model," Acta Anaesthesiologica Scandinavica, vol. 59, no. 4, pp. 448-456, 2015.

[21] S. Livigni, M. Maio, E. Ferretti et al., "Efficacy and safety of a low-flow veno-venous carbon dioxide removal device: results of an experimental study in adult sheep," Critical Care, vol. 10, no. 5, article R151, 2006. 
[22] P. D. Wearden, W. J. Federspiel, S. W. Morley et al., "Respiratory dialysis with an active-mixing extracorporeal carbon dioxide removal system in a chronic sheep study," Intensive Care Medicine, vol. 38, no. 10, pp. 1705-1711, 2012.

[23] A. Zanella, P. Mangili, M. Giani et al., "Extracorporeal carbon dioxide removal through ventilation of acidified dialysate: an experimental study," Journal of Heart and Lung Transplantation, vol. 33, no. 5, pp. 536-541, 2014.

[24] A. Zanella, P. Mangili, S. Redaelli et al., "Regional blood acidification enhances extracorporeal carbon dioxide removal: a 48-hour animal study," Anesthesiology, vol. 120, no. 2, pp. 416424, 2014

[25] A. Pesenti, A. Pelizzola, D. Mascheroni et al., "Low frequency positive pressure ventilation with extracorporeal $\mathrm{CO}_{2}$ removal (LEPPV-ECCO2R) in acute respiratory failure (ARF): technique," Transactions-American Society for Artificial Internal Organs, vol. 27, pp. 263-266, 1981.

[26] T. Kolobow, L. Gattinoni, T. Tomlinson, and J. E. Pierce, "An alternative to breathing," Journal of Thoracic and Cardiovascular Surgery, vol. 75, no. 2, pp. 261-266, 1978.

[27] L. Gattinoni, A. Agostoni, A. Pesenti et al., "Treatment of acute respiratory failure with low-frequency positive-pressure ventilation and extracorporeal removal of $\mathrm{CO}_{2}$," The Lancet, vol. 2, no. 8189, pp. 292-294, 1980.

[28] R. Marcolin, D. Mascheroni, A. Pesenti, M. Bombino, and L. Gattinoni, "Ventilatory impact of partial extracorporeal $\mathrm{CO}_{2}$ removal (PECOR) in ARF patients," ASAIO Transactions, vol. 32, no. 1, pp. 508-510, 1986.

[29] A. Pesenti, G. P. Rossi, P. Pelosi, L. Brazzi, and L. Gattinoni, "Percutaneous extracorporeal $\mathrm{CO}_{2}$ removal in a patient with bullous emphysema with recurrent bilateral pneumothoraces and respiratory failure," Anesthesiology, vol. 72, no. 3, pp. 571573,1990 .

[30] L. Gattinoni, T. Kolobow, G. Damia, A. Agostoni, and A. Pesenti, "Extracorporeal carbon dioxide removal (ECCO2R): a new form of respiratory assistance," International Journal of Artificial Organs, vol. 2, no. 4, pp. 183-185, 1979.

[31] L. Gattinoni, T. Kolobow, T. Tomlinson et al., "Low-frequency positive pressure ventilation with extracorporeal carbon dioxide removal (LFPPV-ECCO2R): an experimental study," Anesthesia and Analgesia, vol. 57, no. 4, pp. 470-477, 1978.

[32] L. Gattinoni, T. Kolobow, T. Tomlinson, D. White, and J. Pierce, "Control of intermittent positive pressure breathing (IPPB) by extracorporeal removal of carbon dioxide," British Journal of Anaesthesia, vol. 50, no. 8, pp. 753-758, 1978.

[33] L. Gattinoni, A. Pesenti, D. Mascheroni et al., "Low-frequency positive-pressure ventilation with extracorporeal $\mathrm{CO}_{2}$ removal in severe acute respiratory failure," The Journal of the American Medical Association, vol. 256, no. 7, pp. 881-886, 1986.

[34] F. Brunet, M. Belghith, J.-P. Mira et al., "Extracorporeal carbon dioxide removal and low-frequency positive-pressure ventilation: improvement in arterial oxygenation with reduction of risk of pulmonary barotrauma in patients with adult respiratory distress syndrome," Chest, vol. 104, no. 3, pp. 889-898, 1993.

[35] Health Quality Ontario, "Extracorporeal lung support technologies-bridge to recovery and bridge to lung transplantation in adult patients: an evidence-based analysis," Ontario Health Technology Assessment Series, vol. 10, no. 5, pp. 1-47, 2010.

[36] E. D. Moloney and M. J. D. Griffiths, "Protective ventilation of patients with acute respiratory distress syndrome," British Journal of Anaesthesia, vol. 92, no. 2, pp. 261-270, 2004.
[37] M. Britos, E. Smoot, K. D. Liu, B. T. Thompson, W. Checkley, and R. G. Brower, "The value of positive end-expiratory pressure and Fio 2 criteria in the definition of the acute respiratory distress syndrome," Critical Care Medicine, vol. 39, no. 9, pp. 2025-2030, 2011.

[38] L. Gattinoni, P. Caironi, M. Cressoni et al., "Lung recruitment in patients with the acute respiratory distress syndrome," The New England Journal of Medicine, vol. 354, no. 17, pp. 1775-1786, 2006.

[39] T. J. Nuckton, J. A. Alonso, R. H. Kallet et al., "Pulmonary deadspace fraction as a risk factor for death in the acute respiratory distress syndrome," The New England Journal of Medicine, vol. 346, no. 17, pp. 1281-1286, 2002.

[40] The ARDS Definition Task Force, "Acute respiratory distress syndrome: the Berlin definition," The Journal of the American Medical Association, vol. 307, no. 23, pp. 2526-2533, 2012.

[41] P. P. Terragni, G. Rosboch, A. Tealdi et al., "Tidal hyperinflation during low tidal volume ventilation in acute respiratory distress syndrome," American Journal of Respiratory and Critical Care Medicine, vol. 175, no. 2, pp. 160-166, 2007.

[42] F. Brunet, J.-P. Mira, M. Belghith et al., "Extracorporeal carbon dioxide removal technique improves oxygenation without causing overinflation," American Journal of Respiratory and Critical Care Medicine, vol. 149, no. 6, pp. 1557-1562, 1994.

[43] A. H. Morris, C. J. Wallace, R. L. Menlove et al., "Randomized clinical trial of pressure-controlled inverse ratio ventilation and extracorporeal $\mathrm{CO}_{2}$ removal for adult respiratory distress syndrome," American Journal of Respiratory and Critical Care Medicine, vol. 149, no. 2, part 1, pp. 295-305, 1994.

[44] R. M. Muellenbach, M. Kredel, C. Wunder et al., "Arteriovenous extracorporeal lung assist as integral part of a multimodal treatment concept: A retrospective analysis of 22 patients with ARDS refractory to standard care," European Journal of Anaesthesiology, vol. 25, no. 11, pp. 897-904, 2008.

[45] J. B. Zwischenberger, S. A. Conrad, S. K. Alpard, L. R. Grier, and A. Bidani, "Percutaneous extracorporeal arteriovenous $\mathrm{CO}_{2}$ removal for severe respiratory failure," Annals of Thoracic Surgery, vol. 68, no. 1, pp. 181-187, 1999.

[46] P. P. Terragni, L. Del Sorbo, L. Mascia et al., "Tidal volume lower than $6 \mathrm{ml} / \mathrm{kg}$ enhances lung protection: role of extracorporeal carbon dioxide removal," Anesthesiology, vol. 111, no. 4, pp. 826835, 2009.

[47] T. Bein, S. Weber-Carstens, A. Goldmann et al., "Lower tidal volume strategy $\left(\approx 3 \mathrm{ml} / \mathrm{kg}\right.$ ) combined with extracorporeal $\mathrm{CO}_{2}$ removal versus 'conventional' protective ventilation $(6 \mathrm{ml} / \mathrm{kg})$ in severe ARDS: the prospective randomized Xtravent-study," Intensive Care Medicine, vol. 39, no. 5, pp. 847-856, 2013.

[48] G. W. Hoo, N. Hakimian, and S. M. Santiago, "Hypercapnic respiratory failure in COPD patients: response to therapy," Chest, vol. 117, no. 1, pp. 169-177, 2000.

[49] R. Menzies, W. Gibbons, and P. Goldberg, "Determinants of weaning and survival among patients with COPD who require mechanical ventilation for acute respiratory failure," Chest, vol. 95, no. 2, pp. 398-405, 1989.

[50] D. Makris, B. Desrousseaux, E. Zakynthinos, A. Durocher, and S. Nseir, "The impact of COPD on ICU mortality in patients with ventilator-associated pneumonia," Respiratory Medicine, vol. 105, no. 7, pp. 1022-1029, 2011.

[51] S. Nseir, C. Di Pompeo, S. Soubrier et al., "Impact of ventilatorassociated pneumonia on outcome in patients with COPD," Chest, vol. 128, no. 3, pp. 1650-1656, 2005. 
[52] D. C. Abrams, K. Brenner, K. M. Burkart et al., "Pilot study of extracorporeal carbon dioxide removal to facilitate extubation and ambulation in exacerbations of chronic obstructive pulmonary disease," Annals of the American Thoracic Society, vol. 10, no. 4, pp. 307-314, 2013.

[53] R. Roncon-Albuquerque, G. Carona, A. Neves et al., "Venovenous extracorporeal $\mathrm{CO}_{2}$ removal for early extubation in COPD exacerbations requiring invasive mechanical ventilation," Intensive Care Medicine, vol. 40, no. 12, pp. 1969-1970, 2014.

[54] N. K. Burki, R. K. Mani, F. J. F. Herth et al., "A novel extracorporeal $\mathrm{CO}_{2}$ removal system: results of a pilot study of hypercapnic respiratory failure in patients with COPD," Chest, vol. 143, no. 3, pp. 678-686, 2013.

[55] S. Cole, N. A. Barrett, G. Glover et al., "Extracorporeal carbon dioxide removal as an alternative to endotracheal intubation for non-invasive ventilation failure in acute exacerbation of COPD," Journal of the Intensive Care Society, vol. 15, no. 4, pp. 344-346, 2014.

[56] S. Kluge, S. A. Braune, M. Engel et al., "Avoiding invasive mechanical ventilation by extracorporeal carbon dioxide removal in patients failing noninvasive ventilation," Intensive Care Medicine, vol. 38, no. 10, pp. 1632-1639, 2012.

[57] L. Del Sorbo, L. Pisani, C. Filippini et al., "Extracorporeal $\mathrm{Co}_{2}$ removal in hypercapnic patients at risk of noninvasive ventilation failure: a matched cohort study with historical control," Critical Care Medicine, vol. 43, no. 1, pp. 120-127, 2015.

[58] R. Roncon-Albuquerque Jr. and D. Brodie, "Extracorporeal $\mathrm{Co}_{2}$ removal in severe chronic obstructive pulmonary disease exacerbations: a work in progress," Critical Care Medicine, vol. 43, no. 3, pp. e102-e103, 2015.

[59] K. Wiebe, J. Poeling, M. Arlt et al., "Thoracic surgical procedures supported by a pumpless interventional lung assist," Annals of Thoracic Surgery, vol. 89, no. 6, pp. 1782-1788, 2010.

[60] P. Schellongowski, K. Riss, T. Staudinger et al., "Extracorporeal $\mathrm{CO}_{2}$ removal as bridge to lung transplantation in lifethreatening hypercapnia," Transplant International, vol. 28, no. 3, pp. 297-304, 2015.

[61] D. Ricci, M. Boffini, L. Del Sorbo et al., "The use of $\mathrm{CO}_{2}$ removal devices in patients awaiting lung transplantation: an initial experience," Transplantation Proceedings, vol. 42, no. 4, pp. 1255-1258, 2010. 


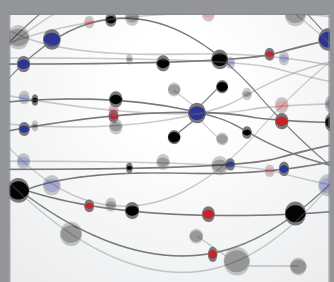

The Scientific World Journal
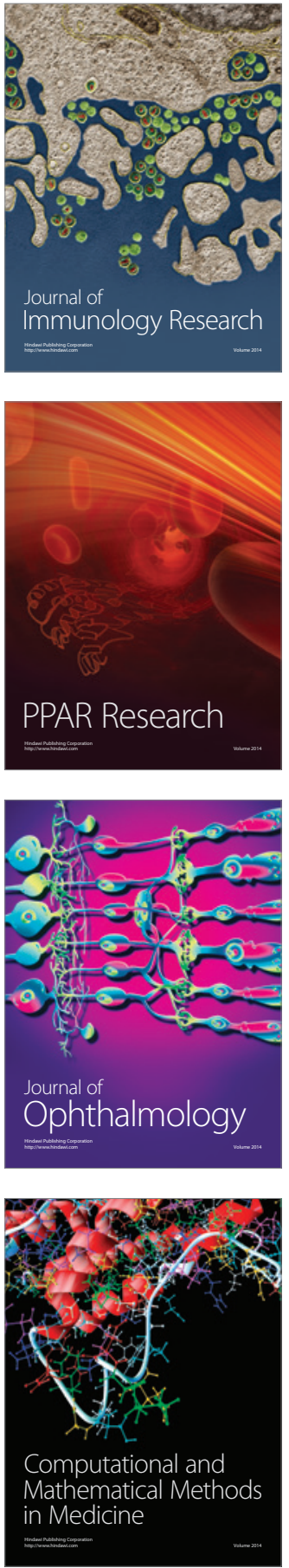

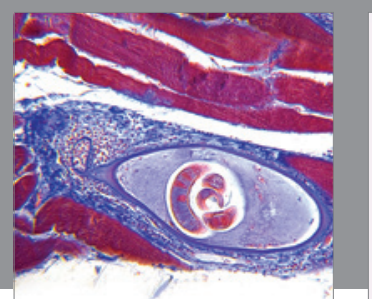

Gastroenterology Research and Practice

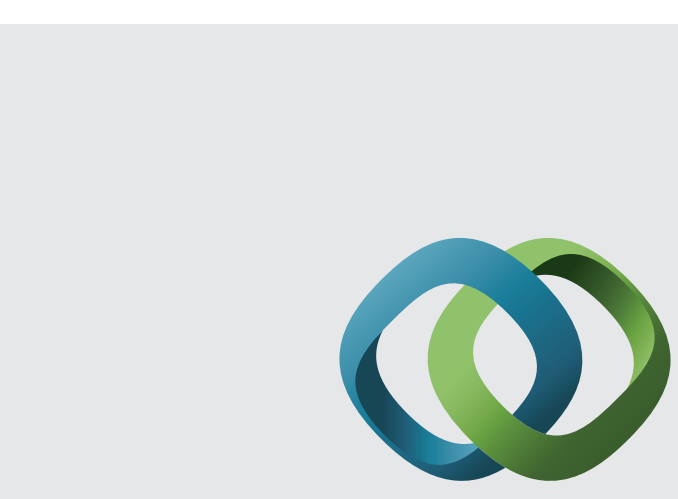

\section{Hindawi}

Submit your manuscripts at

http://www.hindawi.com
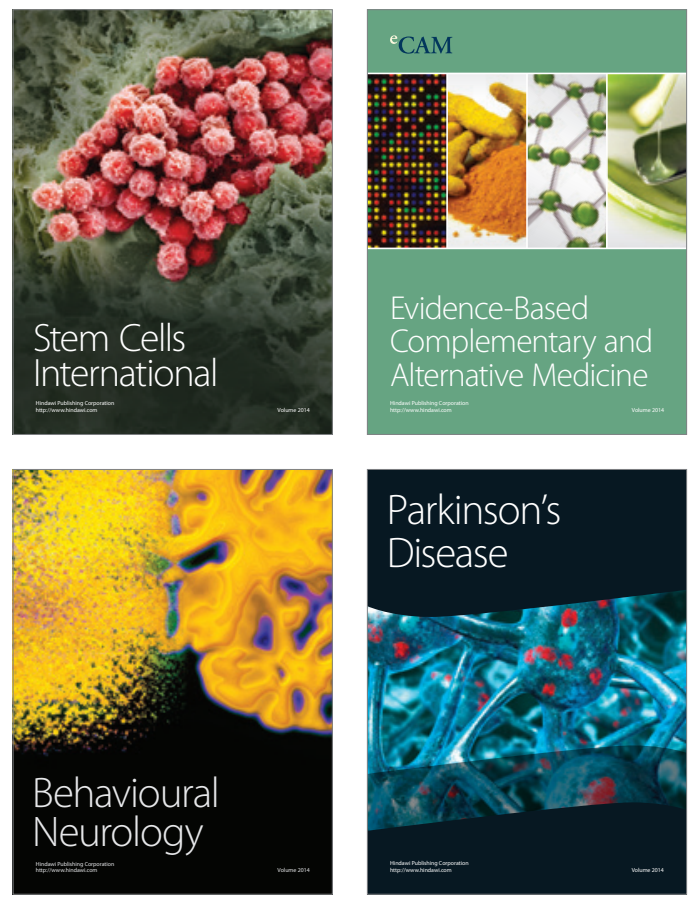
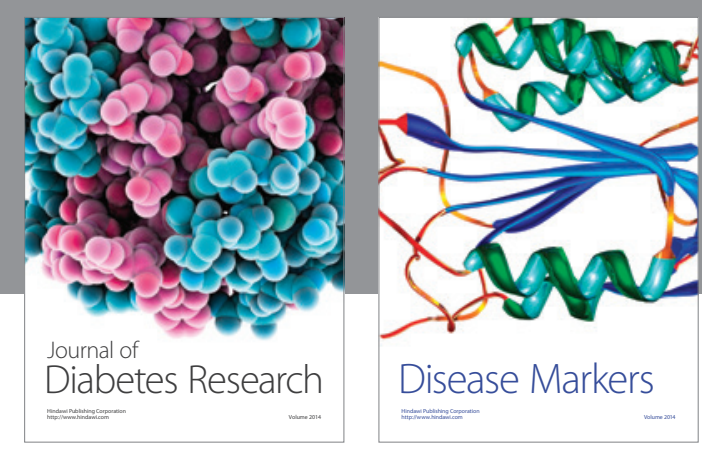

Disease Markers
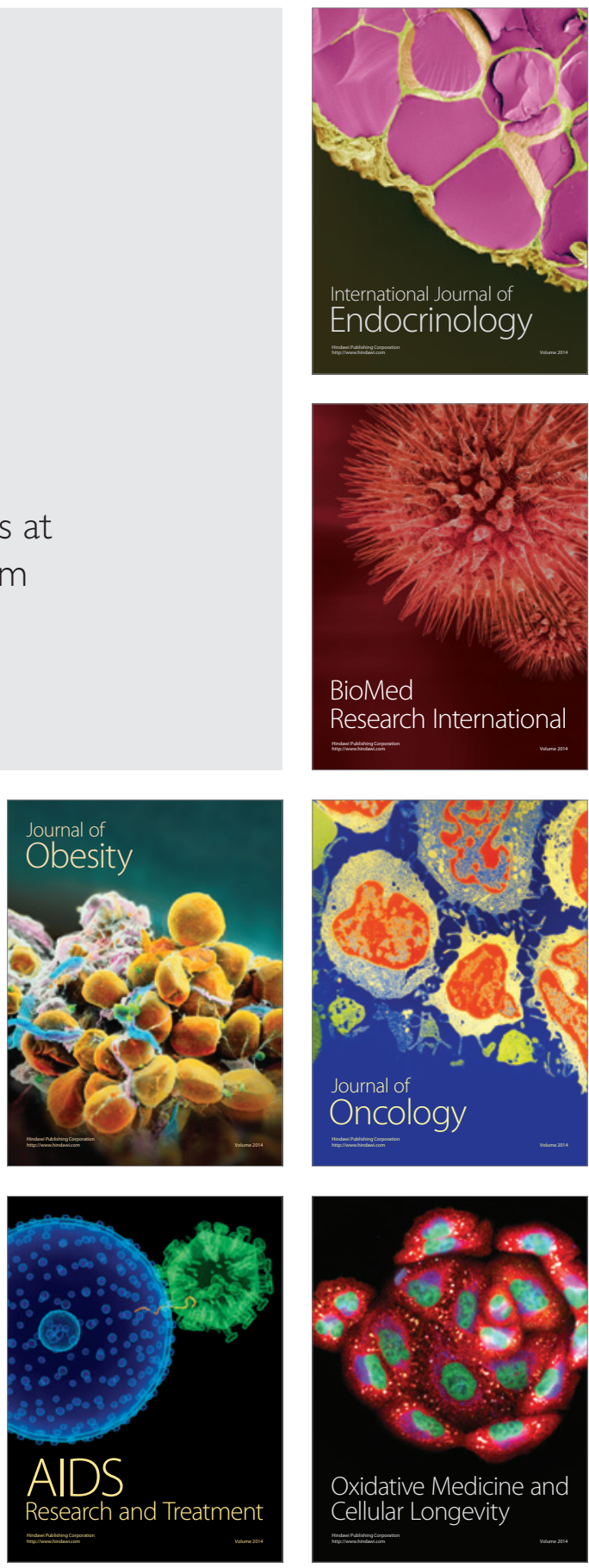